\title{
Study on Influence Factors of Technology Innovation Efficiency in China's Manufacturing Industry
}

\author{
Danqing $\mathrm{Li}^{1, \mathrm{a}}$, Xiaojuan $\mathrm{He}^{\mathrm{*}^{2, \mathrm{~b}}}$ \\ ${ }^{1}$ Wuhan Donghu University, Economic Department, Wuhan 430212, China \\ ${ }^{2}$ Wuchang University of Technology, Business Department, Wuhan 430223, China \\ adanqing2016@qq.com, b472978562@qq.com
}

Keywords: Manufacturing industry, Technology innovation efficiency, Trans-long production function; Stochastic frontier analysis (SFA).

\begin{abstract}
Based on the approach of Stochastic Frontier Analysis and adopting the model of Trans-long Production Function, using the panel data of 25 manufacturing industries from 2009 to 2015 in China, this paper measures the technology innovation efficiency and analyzes influence factors of domestic enterprises. The results show that there is technological innovation inefficiency in domestic enterprises of manufacturing during 2009 to 2015. In terms of the factors that influence technology innovation efficiency, enterprise scale, market structure, technology acquisition and retrofit costs have positive effects on technology innovation efficiency, while export-oriented degree have negative and profitability has no significant effect on technological efficiency.
\end{abstract}

\section{Introduction}

The manufacturing industry is the foundation of the country, rejuvenation of the device, the foundation of great power. At present, China's total manufacturing industry ranks first in the world, and the manufacturing sector accounts for more than $30 \%$ of the proportion of GDP. However, the level of technological innovation in China's manufacturing industry is still far behind the developed countries. The extensive development mode which relies on the labor force and natural resources makes the added value of China's manufacturing industry very low and international competitiveness lacks. "Made in China 2025" pointed out that the deep fusion of the new generation of information technology and the manufacturing industry is causing far-reaching changes in the industry and comes into being a new mode of production, industrial form, business model and economic growth point [1]. In this background, in order to improve international competitiveness of China's manufacturing industry, it's necessary to promote the development of manufacturing technology innovation and enhance the manufacturing technology innovation ability. In this context, it is of great realistic significance to study the efficiency and its influencing factors of Chinese manufacturing technology innovation.

Technology innovation efficiency (for short TIE), first proposed by Afriat (1972), refers to the technical efficiency of R\&D innovation activities. At present, there are two main methods to measure the efficiency of technological innovation: one is the parameter method, such as the stochastic frontier analysis (SFA), which is come up by Aigner (1997) etc [2]. Some scholars such as Wen X, Gaobang L (2014)[3], and Zedong N, Qianxiao Z (2012)[4] etc. used this method to measure the technology innovation efficiency. The other is a non parametric method, such as data envelopment analysis (DEA) come up by Chames (1978)[5]. Wang Hailong (2016), Liu Yingchun (2016) etc. used this method to measure the technology innovation efficiency. In comparison, the SFA method is more robust than the DEA method, and can be used to determine the usefulness of the model in terms of various statistical tests. So this paper uses the SFA analysis method. 


\section{Model Building and Variables Selection}

Model Building. According to above analysis, this section uses the stochastic frontier analysis method (SFA) to analyze the technology innovation efficiency of different industries in manufacturing. The general form of stochastic frontier analysis method is:

$$
y_{i t}=f\left(x_{i t}, \beta\right) \exp \left(v_{i t}-u_{i t}\right)
$$

In the Eq. (1), y represents output variables, $x$ represents input variables, i represents different industries in manufacturing, $\mathrm{t}$ represents time, $\beta$ represents parameters to be estimated, $\left(\mathrm{v}_{\mathrm{it}}-\mathrm{u}_{\mathrm{it}}\right)$ represents composite disturbance, $v_{i t}$ and $u_{i t}$ are independent of each other. $v_{i t}$ represents random error term and $\mathrm{u}_{\mathrm{it}}$ is technical error term.

The expression of technology innovation efficiency $\mathrm{TE}_{\mathrm{it}}$ is as below:

$$
T E_{i t}=\frac{y_{i t}}{f\left(x_{i t}, \beta\right) \exp \left(v_{i t}\right)}=\frac{f\left(x_{i t}, \beta\right) \exp \left(v_{i t}\right) \exp \left(-u_{i t}\right)}{f\left(x_{i t}, \beta\right) \exp \left(v_{i t}\right)}=\exp \left(-u_{i t}\right)
$$

In the Eq.(2), when $u_{i t}>0, T E_{i t}<1$, indicating that there are technical efficiency in the production activity in the manufacturing industries.

This paper uses trans-log production function of stochastic frontier approach:

$$
\ln Y_{i t}=\beta_{0}+\beta_{1} \ln R D_{i t}+\beta_{2} \ln R D P_{i t}+\frac{1}{2} \beta_{3}\left(\ln R D_{i t}\right)^{2}+\frac{1}{2} \beta_{4}\left(\ln R D P_{i t}\right)^{2}+\beta_{5} \ln R D_{i t} \ln R D P_{i t}+V_{i t}-U_{i t}
$$

In the Eq. (3), Y, RD, RDP respectively new products' sales income, R\&D capital investment and $R \& D$ personnel investment. i represents different industries and t represents different years. $\beta_{0}$ is constant term and $\beta$ is vector to be estimated. $\left(V_{i t}-U_{i t}\right)$ represents stochastic error term of the model.

Variables Selection. This paper focuses on some factors' impact on technology inefficiency, these factors including market structure, export orientation, enterprise scale, technology acquisition and modification and enterprises' profitability. So the inefficiency function is established as follows:

$$
M_{i t}=\lambda_{0}+\lambda_{1} S C A L E_{i t}+\lambda_{2} M S_{i t}+\lambda_{3} E_{X P O R T}+\lambda_{4} T_{E C H}+\lambda_{5} P_{R O F I T}+\varepsilon_{i t}
$$

In the Eq.(4), $\lambda_{0}$ represents constants to be estimated, SCALE, MS, EXPORT, TECH, PROFIT respectively represent enterprise scale, market structure, export orientation, technology acquisition and modification, enterprises' profitability. $\lambda_{1}, \lambda_{2}, \lambda_{3}, \lambda_{4}, \lambda_{5}$ respectively represents the coefficients of the above five variables. $\varepsilon_{\text {it }}$ is the stochastic error term and obey the normal distribution $N(0$, $\left.\sigma_{\varepsilon}^{2}\right)$.

Innovation Input and Innovation Output include Y, RD and RDP.

(1) Innovation output (Y). This paper uses new product sales income to measure technology innovation output .

(2) Innovation R\&D capital input (RD). This paper uses perpetual inventory method, and the calculation Eq. is as follows:

$$
R D_{i t}=(1-\delta) R D_{i(t-1)}+E_{i t}
$$

In Eq. (5), $R D_{i t}$ represents $R \& D$ capital inventory of the industry i in the year $t$ after dealing with the deflator; while $E_{i t}$ represents R\&D capital input of the industry i in the year $\mathrm{t} ; \delta$ is the rate of depreciation. Using 2009 as base year, it assumes that the growth rate of $R \& D$ capital is equal to the rate of growth of $E$. The initial value of $R \& D$ is $R D_{i 0}=\frac{E_{i 0}}{(g+\delta)}$, and $g$ is the average annual growth rate of $E$. The depreciation rate of $\mathrm{R} \& \mathrm{D}$ capital is set to $15 \%$, which referred to the processing method of Yanbing W and Zengyu M (2008) [7].

In the case of building R\&D price index, according to the National Bureau of Statistics and Ministry of Science and Technology, the spending on labor cost and equipment cost is basically the same in 2009-2015. In view of this, the fixed asset investment price index and the consumer price index give the same weighting to 0.5 , and R\&D price index $(\mathrm{PI})$ is the average of the two, that is,

$$
P I=(F+C) / 2
$$


In Eq. (6), $\mathrm{F}$ is the fixed asset investment price index and $\mathrm{C}$ is the consumer price index.

(3) Innovation R\&D personnel input (RDP). The total amount of equivalent (human year) of $\mathrm{R} \& \mathrm{D}$ personnel is used to measure $\mathrm{R} \& \mathrm{D}$ personnel investment.

Factors affecting the technology innovation efficiency include: (1) Enterprise Scale (SCALE). This article uses the average enterprise scale of various industries, and measures the size of manufacturing enterprises by the amount of industrial sales divided by the number of enterprises. (2) Market structure (MS). The HHI index is typically used to measure market structure. But because there is no data available in manufacturing, this article uses the number of companies in each industry to approximate the level of competition. (3) Export (EXPORT). This study uses the proportion of export value of total output value to measure the influence of export-oriented factors on different industries in manufacturing. (4) Technology acquisition and modification (TECH). The variable is the sum of the four expenditures: expenditure of technology import, expenditure of digestion \& absorption of the introduced technologies, expenditure of purchasing domestic technology and expenditure of technology reform. (5) Profitability (PROFIT). Some scholars' research showed that the improvement of the industry profitability could help to improve the use efficiency of industry resources and could make industry resources to generate economies of scale, so as to promote the technology innovation efficiency of the whole industry.

\section{Empirical Analysis Results}

After measuring technology innovation efficiency in domestic manufacturing enterprises (We don't list specific data here owing to space reasons), this article analyzes the influence factors of technology innovation efficiency. The following regression results are obtained, see Table 1:

Table 1 Analysis Result of the Influence Factors of Manufacturing Technology Innovation Efficiency in Domestic Enterprises

\begin{tabular}{lll}
\hline SFA & coefficient & t-statistics \\
\hline Constant & $20.4092^{* * *}$ & -11.0402 \\
LnRD & $0.4305^{* *}$ & -2.3302 \\
LnRDP & $0.3451^{* * *}$ & -4.3019 \\
\hline Technical inefficiency function & & \\
Constant & 2.9346 & -1.3902 \\
SCALE & $-0.0225^{* * *}$ & -2.7435 \\
MS & $-0.2109^{* *}$ & -2.2026 \\
EXPORT & -0.0405 & -0.7936 \\
TECH & $-0.8309^{* *}$ & -2.5122 \\
PROFIT & 0.8873 & -0.1692 \\
$\sigma^{2}$ & $0.4102^{* * *}$ & -5.0013 \\
$\gamma$ & $0.8539^{* * *}$ & -3.9833 \\
Unilateral LR Test & 25.3121 & \\
\hline
\end{tabular}

Log likelihood function value

$-42.1543$

Note: The positive coefficients mean that the variable has a negative effect on the efficiency of technological innovation; the negative coefficients mean that the variable has a positive effect on the efficiency of technological innovation. ${ }^{* * *},{ }^{* *}, *$ is respectively marked by a significant percentage of 1 percent, 5 percent and 10 percent.

By analyzing the return results of table 1 , the following conclusions can be drawn:

(1) The output elasticity analysis of $R \& D$ input. The result indicates that $R \& D$ capital input is even more important for the promotion of technology innovation efficiency than R\&D personnel input. (2) The impact of SCALE. This suggests that the larger the manufacturing enterprises, the higher the efficiency of technology innovation.(3) The impact of MS. Result shows that the increase 
in the number of manufacturing enterprises in general is conducive to improving the efficiency of technological innovation. (4) The impact of EXPORT. Exports did not promote the efficiency of technological innovation; on the contrary they inhibit the efficiency of technology innovation. (5) The impact of TECH. TECH has a significant positive effect on the efficiency of technological innovation. (6) The impact of PROFIT. The profitability of manufacturing industries (PROFIT) has no significant impact on the efficiency of technological innovation.

\section{Conclusions and Policy Meaning}

Based on the stochastic frontier analysis method, this paper measures the technology innovation efficiency of domestic enterprises in manufacturing and analyzes its influence factors. The basic conclusions are the followings: (1) From 2009 to 2015, there is technology inefficiency in domestic enterprises in manufacturing industry. On the whole, the real technology innovation efficiency is only $60 \%$ to $70 \%$ of the maximum possible level of technology innovation efficiency. (2) In terms of the factors that influence technology innovation efficiency, enterprise scale, market structure, technology acquisition and retrofit costs have positive effects on technology innovation efficiency, while export-oriented degree have negative and profitability has no significant effect on technological efficiency.

Research conclusion of this paper is of important significance on how to improve technology innovation efficiency in domestic enterprises of manufacturing. First, we should increase investment in research and development of domestic enterprises, and also pay more attention to the efficiency of research and development funds. Second, we should broaden the financing channels for middle and small-sized enterprises. Third, we should raise the cost of technology acquisition and transformation. Fourth, we should optimize the export structure of manufacturing. We will guide enterprises to develop industries with higher technology intensity, thus reducing the export proportion of labor-intensive, resource-intensive and low-technology-intensive products.

\section{Acknowledgements}

In this paper, the research was supported by Humanities and Social Science Project of Hubei Education Department (17G079) and Youth Foudation WuHan Donghu University (2017).

\section{References}

[1] Information on http://english.cntv.cn/special/madeinchina/index.shtml

[2] Aigner D. J., Lovell C.A.K., Schmidt P., Formulation and Estimation of Stochastic Frontier Production Function Models [J], Journal of Econometrics, 1977(6):21-37.

[3]Wen X, Gaobang L. Government supports, the efficiency of R\&D management and technological innovation: based on the empirical analysis of China's industrial sector [J], Management World, 2014(04): 71-79. (In Chinese)

[4] Zengdong N, Qianxiao Z. An analysis of technology innovation efficiency of manufacturing equipment industries in China [J], Quantitative \& Technical Economics, 2012(11): 51-67. (In Chinese)

[5] Charmes, A., W. W.Cooper, and E. Rhodes. Measuring the Efficiency of Decision Making Units [J]. European Journal of Operational Research, 1978(2):429-444.

[6] Haili X. Research on the efficiency of equipment manufacturing technology and its influencing factors [J], Science \& Technology Progress and Policy, 2016(03):65-70. (In Chinese)

[7] Yanbing W, Zengyu M. Innovation, imitation and enterprise efficiency: the empirical evidence from non-state owned enterprises [J], 2011(04):77-95. (In Chinese) 